\title{
Pilot of a community-based interprofessional "student-infused" pulmonary rehabilitation program in Saint John, New Brunswick
}

\author{
John R. Doucet, BSc., RRT ${ }^{1}$, Tammie A. Fournier, B.Ed, RRT, FCSRT, CRE, CTE ${ }^{1}$, \\ Christy M. Bishop, BSc., RRT ${ }^{1}$, Derek J. Gaudet, M.A ${ }^{2}$., Daniel A. Nagel, RN, PhD ${ }^{3}$
}

\begin{abstract}
JR Doucet, TA Fournier, CM Bishop, DJ Gaudet, DA Nagel. Pilot of a community-based interprofessional "student-infused” pulmonary rehabilitation program in Saint John, New Brunswick. Can J Respir Ther 2021;57:26-31. doi: 10.29390/cjrt-2020-053.

Background: With the increasing prevalence of chronic pulmonary conditions in New Brunswick and Canada it is necessary to consider innovative interventions to improve access to rehabilitation and supportive care for affected clients. In Fall 2018 we piloted a pulmonary rehabilitation (PR) program for persons with moderate to severe chronic obstructive pulmonary disease (COPD) to demonstrate a novel approach of bridging interprofessional education of students in health care fields with provision of care in a community setting.

Methods: An 8-week PR program was implemented and evaluated using a quasi-experimental design with pre- and post-testing to measure the effects of the program's exercise and educational interventions on persons with COPD. Participants were assessed using the 6-Minute Walk Test (6MWT), the St. George's Respiratory Questionnaire (SGRQ), and a custom questionnaire that rated the participants' activities of daily living and the PR program.

Results: Seven participants completed our PR program. Following the intervention, participants' self-reported health demonstrated a statistically significant improvement. Even though changes on the 6MWT and SGRQ were not shown to be statistically significant, there was evidence of clinically meaningful improvements in those measures. On average, participants walked $25 \mathrm{~m}$ further postintervention and showed clinically meaningful improvements on the SGRQ.

Conclusions: This pilot project demonstrated that a community-based PR program with active involvement of students from multiple health care programs can have positive outcomes for clients with COPD. It also illustrated how educational programs can provide an innovative means for increasing access to rehabilitation and supportive care for clients in the community.
\end{abstract}

Key Words: pulmonary rehabilitation; chronic disease management; interprofessional education; interprofessional collaboration; student-led; student-run

\section{INTRODUCTION}

The prevalence of chronic respiratory conditions, such as chronic obstructive pulmonary disease (COPD), has been increasing in New Brunswick and across Canada. Currently, an estimated 2.6 million Canadians live with COPD with the moderate to severe disease types comprising half of all cases [1]. It is necessary to consider innovative interventions that improve rehabilitation and support care for affected clients, due to the increasing number of COPD cases, access to care, and the escalating cost of care. One novel approach to providing this service through delivery of care to clients with involvement of health care students through experiential learning and interprofessional education (IPE) in the community setting. This serves to provide health care students interdisciplinary hands-on training opportunities and to provide alternative clinical experience outside of the acute care institutions.

In the Fall of 2018 we piloted a pulmonary rehabilitation (PR) program for persons with moderate to severe COPD to demonstrate the feasibility and efficacy of an intervention that involves community collaboration, university participation, and student integration from four interprofessional health care programs.

\section{BACKGROUND}

COPD is an inflammatory condition characterized by airflow limitation and persistent respiratory symptoms [2, 3]. COPD is largely preventable and is most commonly associated with tobacco use; however, environmental exposures and genetic abnormalities may also contribute to its development $[2,3]$. The Canadian Thoracic Society recommends pharmacological and nonpharmacological interventions in the management of Canadians living with COPD such as bronchodilators, self-management education, and pulmonary rehabilitation [4]. Pulmonary rehabilitation $(\mathrm{PR})$ is a nonpharmacological intervention recommended for symptomatic patients to maintain activities of daily living through improvement in dyspnea and exercise tolerance secondary to exercise training and education on disease self-management [4]. Activities in PR programs typically include client education, cardiovascular exercise, and resistance exercise $[3,5-7]$. PR has been found to reduce health care costs through promoting at-home treatment measures and reducing the number of hospital visits $[3,5,8]$. In addition, PR programs have been found to promote other benefits for persons with COPD, such as decreasing anxiety (e.g., related to breathing), alleviating isolation, and increasing motivation in self-care [7, 9].

Canadian PR programs currently have the capacity to see approximately 10,000 patients per year, resulting in only $0.4 \%$ of all Canadians with COPD and $0.8 \%$ of Canadians with moderate to severe COPD having access to this recommended standard of care [5]. Global barriers to PR include low referral rates compared to cardiac rehabilitation, as well as lack of hospital capacity, trained staff, and funding $[4,10]$. One

\footnotetext{
${ }_{1}^{1}$ Allied Health Department, School of Health, New Brunswick Community College, Saint John, Canada

${ }^{2}$ Department of Psychology, University of New Brunswick, Saint John, Canada

${ }^{3}$ College of Nursing, Rady Faculty of Health Sciences, University of Manitoba, Winnipeg, Canada

Correspondence: John R. Doucet, Allied Health Department, School of Health, New Brunswick Community College, 950 Grandview Avenue, Saint John, New Brunswick, Canada, E-mail: John.doucet@nbcc.ca
}

Published online at https://www.cjrt.ca on 17 March 2021 
potential opportunity to expand capacity for providing supportive care to persons with COPD is development of PR programs in the community that involve students in various health care disciplines. This would increase access to rehabilitation for these clients, while also availing students educational opportunities for both practical clinical experience and IPE.

Student-led clinics have been established in Canada and other countries to provide primary care experiential learning in interprofessional teams [11-13]. These clinics serve as a means of addressing educational obligations and community health care concerns, but also present an opportunity for interprofessional practice (IPP) [11, 12, 14]. IPP is a collaborative approach to care that occurs when health care professionals work with their peers, individuals from other health care professions, patients, and their families $[14,15]$. The Canadian Interprofessional Health Collaborative (CIHC) has established a national interprofessional competency framework, designed to serve as the foundation for IPE curricula in all health care professions [15]. The CIHC competency domains cross skill levels, care settings, and contexts of health care professionals; they focus on the development of foundational skills, attitudes, and values that together shape sound clinical judgments within the context of interprofessional collaboration and practice [15].

The overall goal of this project was to pilot implementation of a community-based interprofessional "student-infused" PR program and examine the potential efficacy of such an initiative. We use the term student-infused in recognition that the students were learners, had limited ability to independently provide clinical interventions, required liability coverage, and did not have input to the design of this PR program compared with other student-led initiatives [16-18]. The other objectives of the project were to: $i$ ) create a collaborative IPP opportunity for health care students from a community college and university to work together in the delivery of a PR program and ii) provide experiential learning and first-hand clinical training to students in the provision of care to clients in the community setting.

\section{METHODS}

This pilot study was a pre- and post-test quasi-experimental design conducted at a community college in New Brunswick, Canada. The evaluation of our pilot PR program involved measuring the impact of its interventions on physiological dimensions, health status, and perceptions of participants in the program. Given that a student-infused clinic is a novel approach to the administration of pulmonary rehabilitation, our sample size was limited to what we believed would be necessary to demonstrate efficacy of the program. Approval for the research component and evaluation of the PR program was granted by New Brunswick Community College, Research Ethics Board (File: INT02) in July 2018.

\section{Participants}

Participants were recruited for the program through recommendations from related health care professionals. Inclusion criteria for the PR program were: $i$ ) a diagnosis of moderate or severe COPD, ii) a referral by a respirologist, and iii) the ability to complete a 6 -minute walk test. Exclusion criteria included: $i$ ) a soft tissue injury (e.g., sprain or strain) that could lead to pain during exercise, ii) history of angina in the previous month, iii) a myocardial infarction within the previous month, iv) resting heart rate of more than $120, v$ ) systolic blood pressure of more than $180 \mathrm{~mm} \mathrm{Hg}$, and iv) diastolic blood pressure of more than $100 \mathrm{~mm} \mathrm{Hg}$.

\section{Pulmonary rehabilitation program}

Participants attended an 8-week program consisting of 2-h sessions occurring 3 times a week (i.e., every Monday, Wednesday, and Friday). Each $2-\mathrm{h}$ session included $1 \mathrm{~h}$ of aerobic and resistance training, as well as $1 \mathrm{~h}$ of education that was specific to COPD. Each PR program session was attended by at least one licensed health care professional, who supervised the students from the disciplines of respiratory therapy, nursing, practical nursing, and pharmacy technician. These students were responsible for delivering $100 \%$ of the program under supervision with exception to medication reconciliation, which was conducted by a pharmacist in collaboration with the pharmacy technician students.

Student activities in the PR program included educating participants on the Living Well with COPD curriculum [7, 19], providing lectures, educational materials, and demonstrations of such things as safe exercise and proper inhaler technique/adherence at every occasion. Nursing and respiratory therapy students assessed vital signs throughout the clinic and advised their supervisor of any abnormal results. At each clinic, students led the participants through a basic warm-up, introductory aerobic and strength-training exercises, and then a cool-down.

\section{Measures}

The impact of the program on physiological dimensions, health status, and perceptions were assessed using three measurement tools. These tools were the 6-Minute Walk Test (6MWT), the St. George's Respiratory Questionnaire (SGRQ), and a Self-Reported Health Status (SRHS).

\section{$6 \mathrm{MWT}$}

The 6MWT is indicated for measuring the response to medical interventions in patients with moderate to severe heart or lung disease [20,21]. This test involves asking individuals to walk for $6 \mathrm{~min}$, at their own pace, whereafter a measurement of the distance covered is taken in meters. The 6MWT evaluates the combined responses of the pulmonary and cardiovascular systems to exercise. This includes, but is not limited to, the responses of the systemic circulation, peripheral circulation, and muscle metabolism $[20,21]$. The $6 \mathrm{MWT}$ is one of the most popular clinical exercise tests in respiratory medicine because of its simple testing procedure that eliminates the need for expensive exercise equipment and extensive training for technicians $[20,21]$.

For the 6MWT, the minimal clinically important difference (MCID) is defined as the smallest increase in distance walked that corresponds to the individual's perception that they have improved in their walking ability $[22,23]$. The MCID associated with the 6MWT for stable, severe COPD has been suggested to be an increase of approximately $54 \mathrm{~m} \mathrm{[22].}$ Given the advanced age of this sample, an MCID of 54 m may not readily apply. Research indicates that comorbidities of coronary diseases (unknown here), and other factors, may justify a lesser MCID of only an increase of $25 \mathrm{~m}$ at a much slower pace [23]. This suggests that the particular MCID of the 6MWT used may very well depend on the particular limitation of the participant.

\section{SGRQ}

The SGRQ measures perceptions of health impairment in those with respiratory illness, including (but not limited to) COPD [20, 24, 25]. The SGRQ evaluates perceived disturbances to an individual's overall health, daily activities, and psychosocial state. The SGRQ provides three subscale scores measuring symptoms, activity, and impacts, as well as an overall total score. Low scores on the SGRQ are indicative of a better Health-Related Quality of Life (HRQOL), which refers to an individual or group's perceptions of various components of their physical and mental health over time [26].

As calculating the scores of the SGRQ relies on the use of a specific algorithm that assesses the weights associated with specific answers, scores were computed using an Excel-based scoring calculator before these scores were entered into our statistical software for analysis.

\section{SRHS}

SRHS was assessed using a single Likert-scale item that appeared on the front page of the study measures. This item asked participants to "Please tick in one box to show how you describe your current health"; answers ranged from (1) very good to (5) very poor. Participants completed this item during both pre- and post-intervention stages.

Program Evaluation Questionnaire (PEQ)

This custom-designed questionnaire consisted of six statements, each rated on a five-point Likert-scale from strongly disagree to strongly agree. 
The first item reflected the impact of COPD on their activities of daily living and the other five items captured the participant's opinions on different aspects of student-infused pulmonary rehabilitation activities. The statements were:

1. I believe my activities of daily living are limited by my COPD.

2. A student-led pulmonary rehabilitation program will improve my quality of life.

3. I would recommend a student-led pulmonary rehab program to family and friends.

4. A health care student can provide me with adequate education about COPD.

5. Health care students have the knowledge to answer my questions about COPD.

6. A health care student can lead me through low-intensity exercise.

\section{Procedure}

All participants provided informed consent prior to participating in the study and PR program. Each participant completed the 6MWT, SGRQ, SRHS, and PEQ twice overall, once at the beginning of the program and once at the end. All measures used to evaluate the PR program's efficacy were administered by a member of the research team using a pre- and post-test design. To assess the PR program's overall effect on physical limitations and on participants' HRQOL, the pre- and post-program measures were compared using paired sample t-tests, with a significance level set at $\alpha=0.05$.

\section{RESULTS}

At the outset of the clinic, the cohort consisted of nine participants. Two participants did not complete the 8-week clinic. The final sample consisted of seven individuals, ranging from 61 to 84 years of age $($ mean $=73.71, \mathrm{SD}=8.96)$. Three of the participants were male and the remaining four were female. Two of the participants had a diagnosis of moderate COPD, two were diagnosed with severe COPD, and the remaining three were diagnosed with very severe COPD. Additional evidence of the presence of respiratory illness in the sample was offered by the results of one-sample t-tests comparing the samples pre-intervention Saint George Respiratory Questionnaire scores to normative values $[24,25]$. All scores demonstrated a statistically significant difference from normative values $(P<0.001)$, which suggested that respiratory illness was indeed having a significant impact on their daily lives.

Following the completion of the data collection phase of the project, the data were entered into SPSS and analyses were carried out to assess the efficacy of the student-infused clinic.

\section{MWT}

Results of a paired-sample $t$-test did not demonstrate a statistically significant improvement in performance on the 6MWT $(P=0.123)$. This result is consistent with the fact that patients also did not meet the MCID of $54 \mathrm{~m}$ for the 6MWT suggested by Redemeier et al. [22]. In the present study, participants showed a mean increase of $25.07(\mathrm{SD}=36.99)$ meters. Results of the 6MWT are shown in Figure 1.

\section{SGRQ}

Four paired-sample t-tests were used to determine whether the intervention resulted in a change in any of the four resulting SGRQ scores. None of the four $t$-tests were statistically significant $(P>0.05$ for each SGRQ scale score). We further examined the descriptive statistics, as MCIDs have been established for this measure [25]. Symptoms scores showed a mean reduction of $8.84(\mathrm{SD}=17.15)$ points following the intervention, which is twice the established MCID for this subscale. This result would be interpreted as a moderately efficacious effect. Impact scores also showed a mean reduction of $4.29(\mathrm{SD}=16.90)$ points, which is roughly equivalent to the MCID. This would be considered a slightly efficacious effect on the Impact subscale. Neither of

\section{FIGURE 1}

Results of $6 \mathrm{MWT}$.

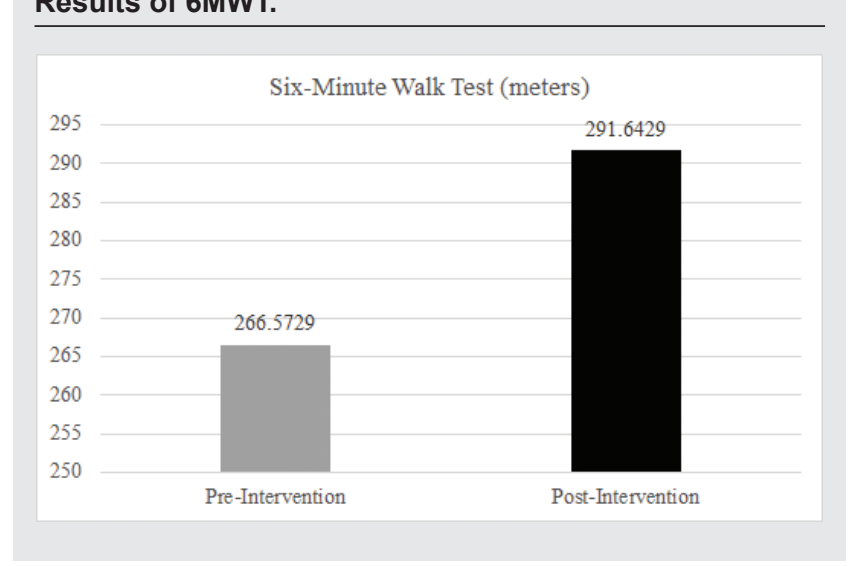

TABLE 1

Paired sample $t$-tests for SGRQ component scores

\begin{tabular}{lccccc}
\hline Component & $\begin{array}{c}\text { Mean score } \\
\text { change }\end{array}$ & SD & $\boldsymbol{t}$ & df & $\boldsymbol{P}$ \\
\hline Symptoms & -8.836 & 17.150 & 1.363 & 6 & 0.222 \\
Activity & 2.850 & 9.390 & -0.803 & 6 & 0.453 \\
Impact & -4.287 & 16.902 & 0.621 & 5 & 0.562 \\
Total & -2.260 & 9.739 & 0.568 & 5 & 0.594 \\
\hline
\end{tabular}

Note: Negative values denote a reduction in score post intervention and, therefore, an improvement in that area of life in COPD patients.

the other two scores showed a change equivalent to or greater than the MCID. The results of the paired sample t-tests and mean change scores are presented in Table 1.

Self-reported health status and evaluation of the program A paired-sample t-test was used to determine whether the seven participants had felt that their health status, as indicated by SRHS, improved following the intervention. The analysis was statistically significant, $t(6)=2.521, P=0.045$. The results suggest an improvement in SRHS. The results of SRHS appear in Table 2 and Figure 2.

We provided participants with a 6-item questionnaire to determine whether opinions on a student-infused respiratory clinic became more or less favourable following their experiences. Six paired-sample t-tests were used to examine each of the items individually. None of the six items were statistically significant $(P>0.05)$, suggesting no change in the participant's opinions of the student-infused clinic. The results of these analyses are presented in Table 2 .

The lack of statistically significant improvement may be because participants rated their initial expectations of the program highly. As a result of this, it may have not been possible for the participant's opinions of the rehabilitation program to become more favourable resulting in a ceiling effect that occurred because the previous measurement was already near the upper limit of the measurement tool. Supporting this possibility, participants responded favourably to the idea of a student-infused clinic prior to receiving care and later attested to the value of this pilot project.

When asked at the end of the questionnaire whether they had any additional comments regarding the PR program, all participants expressed positive perspectives on the initiative. For instance, one participant stated "I love it. I think it is a very good thing. They should not stop the program." Another stated "This program has made it much easier to do things and improved my living so that I feel much better." 
TABLE 2

Paired sample t-tests for pre- and post-participant program evaluations

\begin{tabular}{|c|c|c|c|c|c|c|}
\hline Item & Evaluation & Mean & SD & $t$ & df & $P$ \\
\hline \multicolumn{7}{|l|}{ SRHS } \\
\hline Pre-SRHS & & 3.4286 & 9.759 & 2.521 & 6 & 0.045 \\
\hline Post-SRHS & & 2.5714 & 1.272 & & & \\
\hline \multicolumn{7}{|l|}{ Participant Evaluation Questionnaire } \\
\hline \multirow[t]{2}{*}{ I believe my activities of daily living are limited by my COPD. } & Pre & 4.286 & 0.756 & 0.420 & 6 & 0.689 \\
\hline & Post & 4.143 & 0.690 & & & \\
\hline \multirow[t]{2}{*}{ A student-led pulmonary rehabilitation program will improve my quality of life. } & Pre & 4.286 & 0.488 & -2.121 & 6 & 0.078 \\
\hline & Post & 4.714 & 0.488 & & & \\
\hline \multirow[t]{2}{*}{ I would recommend a student-led pulmonary rehab program to family and friends. } & Pre & 4.143 & 0.690 & -1.922 & 6 & 0.103 \\
\hline & Post & 4.714 & 0.488 & & & \\
\hline \multirow[t]{2}{*}{ A healthcare student can provide me with adequate education about COPD. } & Pre & 4.286 & 0.488 & -1.000 & 6 & 0.356 \\
\hline & Post & 4.429 & 0.535 & & & \\
\hline \multirow[t]{2}{*}{ Healthcare students have the knowledge to answer my questions about COPD. } & Pre & 4.000 & 0.817 & -2.121 & 6 & 0.078 \\
\hline & Post & 4.429 & 0.535 & & & \\
\hline \multirow[t]{2}{*}{ A healthcare student can lead me through low-intensity exercise. } & Pre & 4.286 & 0.488 & -2.121 & 6 & 0.078 \\
\hline & Post & 4.714 & 0.488 & & & \\
\hline
\end{tabular}

Note: Means and standard deviations reported represent pre and post descriptives.

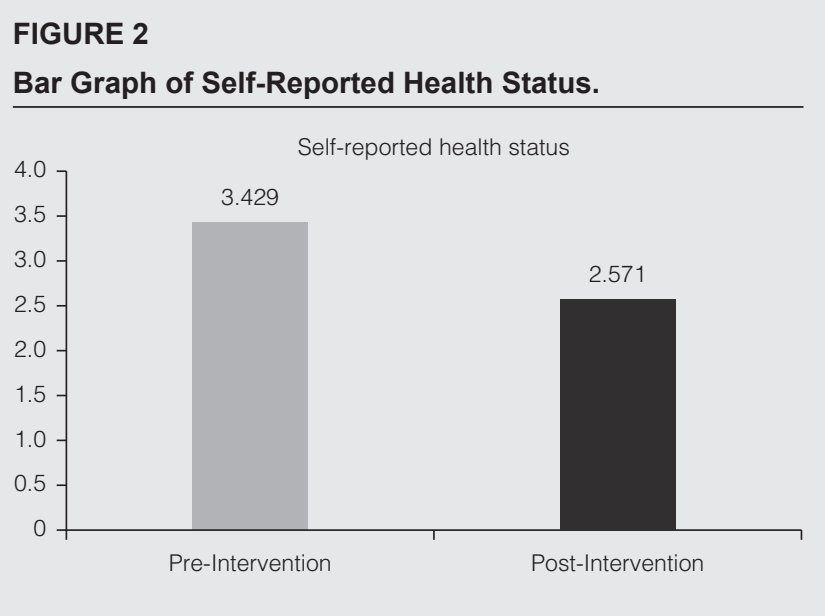

\section{DISCUSSION}

Overall, this pilot project demonstrated that a community-based PR program with active involvement of students from a variety of health care programs can have positive outcomes for clients with COPD. It also illustrated how educational programs for health care students can provide an innovative means for increasing access to rehabilitation and supportive care for clients in the community. Although the sample size for this pilot project was small, which affected our ability to detect statistically significant differences within some of the measures, participants did show a clinically meaningful improvement in the 6MWT. As well, the SGRQ provided evidence that participant's perceptions of their overall health may have improved following the 8-week clinic. Participants also responded favourably to the concept of a student-infused clinic, describing positive experiences when receiving education and guidance from the students. Three key learnings from our pilot project are: $i$ ) the potential for student-infused, community-based PR clinics to improve client health outcomes; ii) the feasibility of offering these services in a community setting; and iii) the ability to bridge education and health care delivery for students in health disciplines.

Our pilot project demonstrated that a PR program incorporating students in a mix of health care disciplines can deliver interventions that result in positive client health outcomes. While a more robust study with a larger sample size is necessary to more accurately measure the effect of the program's exercise and health promotion interventions, improvements in activity levels and perceived health support the principle that students can promote positive health outcomes with clients who have COPD. This is congruent with outcomes of other student-led or student-run clinics, where outcomes in various interventions were demonstrated to have increased physiological, knowledge, and QoL outcomes for clients in relation to activities such as exercise, medication reconciliation, and health education $[13,14]$.

As this was an 8-week intervention, one aspect of outcomes that would be good to capture is the long-term benefits of a PR program given the chronicity of COPD. In 2013, Ouyang et al. [13] found that sustained positive outcomes, such as maintaining knowledge on focused topics (e.g., health information), can be achieved in the context of student-run clinics. Exploration of sustained outcomes, such as knowledge retention and health management practices, in the context of PR would be beneficial in future offerings of a similar program.

Though not directly addressed in this project, our team also observed increased social interaction, both participant-to-participant and participant-to-student, as the weekly sessions progressed. PR appears to provide participants with the opportunity to support each other and thus overcome feelings of social isolation. It is possible the participants benefited from social aspects of the program through interactions with peers, students, and/or facilitators [6, 27]. Known benefits of PR include improved quality of life, decrease in symptoms of disease, enhanced emotional function, and reduction in social isolation often associated with COPD [3, 5]. However, there seems to be little literature available to describe the relationships of participants with peers and students or the effects on mental health as a part of health outcomes in PR and similar programs.

When considering the feasibility of offering the PR program and the practicalities of implementing this service in a community setting, many factors were considered in relation to the formation of interprofessional and interdisciplinary partnerships, support for the program (e.g., key stakeholders and participants), finances, and logistics. One driving force for strong support of the PR program included co-location of two health education institutions and a regional hospital that already shared IPE activities beginning in year one of the various programs and committed faculty who had an interest in health promotion, research, and interprofessional collaboration. This strength combined with a need for student clinical placements and a gap in rehabilitation services within our health care system helped forge collaborative partnerships between the education institutions and important stakeholders, such as the local health authority and pulmonary specialists.

Financial support for our pilot PR program was primarily received through a federal innovation fund, but also included a funding contribution from advanced education and in-kind donations from industry partners. This funding covered staffing, equipment costs, and knowledge dissemination, while much of the planning, student precepting, and 
research time by faculty was absorbed into existing workload or through voluntary service. Although initial start-up costs for the first clinic mainly involved capital expenses for purchase of large fitness equipment and other infrastructure needs (e.g., recumbent bicycle, free weights, oximetry units), we anticipate ongoing clinic material costs will largely involve consumable supplies (e.g., cleaning supplies, oxygen, personal protective equipment) that are a relatively minimal expense. One significant cost for an ongoing PR program would be the salary of a consistent health care professional to coordinate and oversee the operations; however, it is possible that an integrated and collaborative approach among educational institutions, the health sector, and other community stakeholders could minimize costs and help facilitate long-term sustainability while addressing a gap in health services to underserved populations [17, 28]. There is scant literature reflecting the long-term economic, educational, and health outcome impact of student-infused programs, but we hypothesize that the costs of an ongoing PR program will likely outweigh the exponential benefits produced for the community.

There were several logistical barriers and considerations that arose in the planning and implementation of our pilot PR program. First was the location and physical space to ensure access and safety for the participants and to accommodate execution of the intervention. It was essential that space for the program be located on a ground floor next to a major entrance and adjacent to a washroom to accommodate potential mobility challenges of participants. Structural considerations such as free parking, access, and timing of programs have been identified as either anticipated factors or known to be an impediment to participation and retention of clients in similar programs [8-10, 27]. To that end, we either assisted participants by parking their vehicle for them or absorbed transit costs to decrease physical and economic barriers to the program. Lastly, one challenge with our location was lack of supplemental oxygen on site given the community setting. This is a common issue across Canada: $15 \%$ of Canadian PR programs do not have access to supplemental oxygen [5]. We remedied this situation by using refillable oxygen cylinders that likely will be required in most community settings. Other safety measures taken into consideration included having emergency protocols in place and access to an automatic external defibrillator.

As a proof of concept, our PR program was an experiential learning opportunity that actively engaged students across four different health care professions and from two different post-secondary institutions in its operation. The PR program was piloted to both address the shortage of pulmonary rehabilitation in Saint John and provide an interprofessional learning experience in a real-time community clinical placement. As such, our pilot addressed both IPE entry-to-practice requirements in the students' curricula and a shortage of community clinical placements for health students. Competency requirements for IPE are mandated for core entry-to-practice curricula across various health care disciplines (i.e., licensed practical nursing, respiratory therapy, and nursing) in Canada [29-31] and, although mastery in interprofessional collaboration does not occur at entry to practice, it is a skill that continues to develop throughout an individual's education and career as a health care professional [15].

While students operated in integrated teams to represent and share perspectives through their disciplinary lens as part of professional development, they also had the opportunity to utilize their skills and knowledge to engage clients in community outside of the traditional acute setting. Historically, many student-led clinics have been designed and implemented in community settings external to formal curricula and student assessments [11, 17, 18]; however, our pilot PR program demonstrates the potential for ongoing community clinical practicums as part of regular IPE for health care students. Similar experiential educational models that incorporate IPE into curricula of health discipline programs have enhanced student professional development, created alternative clinical placements, and benefited clients with diverse needs in the community $[12,14,16]$.

\section{Limitations}

A limitation of our pilot study was the small sample size, which can result in low statistical power. Low statistical power in the present study means that we may have missed true differences between pre- and post-test results on some of the measures that would have helped to establish the efficacy of this health intervention. Future studies will need to validate the efficacy of student-infused PR programs using larger sample sizes. This is to ensure that any real effect of the program on patient outcomes is detected as well as in allowing for generalizability of the results.

Another limitation was our ability to validate and contextualize the participant's evaluation of the PR program using the current questionnaire. For instance, we only asked one question related to the participants' receptivity of student involvement that was overwhelmingly positive and congruent with findings of another study [16]. It would be helpful to understand specifically why participants were receptive to students and what they contributed to COPD management. Revision of the questionnaire and addition of qualitative questions would enhance the exploration of the participant's experience of a student-infused PR program.

Finally, there was no evaluation of the student learning experience while participating in the pilot or of the impact of IPE to assess the educational value of a student-infused PR program. Addition of a validated IPE survey and qualitative interviews of participating students would contribute to our knowledge of integrating similar programs into curriculum of healthcare students.

\section{Future directions for research}

In addition to addressing the preceding limitations, considerations for future research arose through anecdotal observations by our team related to participant interactions with students and with each other. Participants appeared to genuinely appreciate the attention provided by students and seemed quite comfortable receiving education and coaching from students. Other studies have found that participants value the thoroughness of assessments and interventions provided by students [16, 32]. However, it cannot be determined whether participants are more comfortable solely with the students versus with health care professionals.

In relation to participant interactions with peers during PR program sessions, a high degree of social engagement seemed to develop over time including friendly competitiveness between participants for walking distance and endurance. There is some evidence on the impact of socialization on participants during student-infused health initiatives in relation to isolation, sense of confidence, and peer support [9]; however, further knowledge is needed to fully understand the impact that similar PR programs can have on mental health and overall well-being. Finally, it would be beneficial to understand more about the impact of moving PR program interventions out of hospitals and into the community settings with regards to attendance of sessions, client uptake of health education, long-term adherence to chronic disease management interventions, and overall health outcomes.

\section{CONCLUSION}

Our pilot initiative demonstrated a successful implementation of an interprofessional community-based student-infused PR program through a collaborative effort of two educational institutions and other stakeholders. Although further research using larger sample sizes is required to evaluate the statistical significance of the PR program interventions, the positive outcomes for participants that resulted from direct student participation as part of a more formal experiential and interprofessional learning experience were evident. Further exploration to understand participant perceptions on student contributions to COPD management would be beneficial in a future study. In addition, our pilot study illustrates the potential to integrate a formalized model of education that builds on traditional models of student-led or student-run clinics to provide IPE clinical practice experiences while also addressing gaps in the current health care system. With the increasing prevalence of chronic pulmonary conditions in New Brunswick and Canada, it is necessary to consider this innovative intervention as a potential tool for improving access to rehabilitation and supportive care for affected clients, and to prepare future graduates in health care fields with beginning competencies in IPE through experiential education. 


\section{DISCLOSURES}

\section{Acknowledgments}

The authors would like to thank all students who participated from the following programs: Respiratory Therapy, Practical Nurse, and Pharmacy Technician at the New Brunswick Community College, Saint John Campus, as well as students from the Bachelor of Nursing Program at the University of New Brunswick, Saint John. The authors would also like to thank Dan Corey, Jennifer Rooney, Lisa Curtis, Robyn Palk, and Jennifer Brown.

\section{Conflict of interest}

No authors have any conflict of interests with any external agencies.

\section{Funding}

This study was carried out with funding from the College and Community Innovation Social Innovation Fund (supported by Canadian Institutes of Health Research) as well as the Post-Secondary Education Regional Collaboration Group. In-kind contributions of equipment were received from Quality Respiratory Care, Saint John, New Brunswick; in-kind contributions of Certified Respiratory Educators were received from Horizon Health Network.

\section{REFERENCES}

1. Evans J, Chen Y, Camp PG, Bowie DM, McRae L. Estimating the prevalence of COPD in Canada: reported diagnosis versus measured airflow obstruction. Health Rep 2014;25(3):3-12.

2. Alvar A, Decramer M, Frith P. Global initiative for chronic obstructive lung disease. Pocket guide to COPD diagnosis, management and prevention. Global Initiative for Chronic Obstructive Lung Disease. 2017;1:42.

3. O'Donnell DE, Aaron S, Bourbeau J, et al. Canadian thoracic society recommendations for management of chronic obstructive pulmonary disease - 2007 update. Can Respir J 2007;14(Suppl B):5B-32B. doi: $10.1155 / 2007 / 830570$.

4. Bourbeau J, Bhutani M, Hernandez P, et al. CTS position statement: pharmacotherapy in patients with COPD - an update. Can J Respir Crit CareSleepMed2017;1(4);222-241.doi: 10.1080/24745332.2017.1395588.

5. Camp PG, Hernandez P, Bourbeau J, et al. Pulmonary rehabilitation in Canada: a report from the Canadian thoracic society COPD clinical assembly. Can Respir J 2015;22. doi: 10.1155/2015/369851.

6. Williams V, Bruton A, Ellis-Hill C, McPherson K. The effect of pulmonary rehabilitation on perceptions of breathlessness and activity in COPD patients: a qualitative study. Prim Care Respir J 2010;19(1):45-51. doi: $10.4104 /$ pcrj.2009.00044.

7. Cosgrove D, MacMahon J, Bourbeau J, Bradley JM, O’Neill B. Facilitating education in pulmonary rehabilitation using living well with COPD programme for pulmonary rehabilitation: a process evaluation. BMC Pulm Med 2013;13:50. doi: 10.1186/1471-2466-13-50.

8. Vogiatzis I, Rochester CL, Spruit MA, Troosters T, Clini EM. Increasing implementation and delivery of pulmonary rehabilitation: key messages from the new ATS/ERS policy statement. Eur Respir J 2016;47:1336-1341. doi: 10.1183/13993003.02151-2015.

9. Kirkpatrick P, Wilson E, Wimpenny P. Support for older people with COPD in community settings: a systematic review of qualitative research. JBI Libr Syst Rev 2012;10(57):3649-3763. doi: 10.11124/jbisrir-2012-6.

10. Alsubaiei ME, Cafarella PA, Frith PA, McEvoy RD, Effing TW. Barriers for setting up a pulmonary rehabilitation program in the Eastern Province of Saudi Arabia. Ann Thorac Med 2016;11(2):121. doi: 10.4103/1817-1737.180028.

11. Farlow JL, Goodwin C, Sevilla J. Interprofessional education through service-learning: lessons from a student-led free clinic. J Interprof Care 2015;29(3):263-4. doi: 10.3109/13561820.2014.936372.

12. Kent F, Martin N, Keating JL. Interprofessional student-led clinics: an innovative approach to the support of older people in the community. J Interprof Care 2016;30(1):123-8. doi: 10.3109/13561820.2015. 1070133.

13. Ouyang D, Yuan N, Sheu L, Lau G, Chen C, Lai CJ. Community health education at student-run clinics leads to sustained improvement in patients' hepatitis B knowledge. J Community Health 2013;38(3):471-9. doi: 10.1007/s10900-012-9631-3.

14. Nagelkerk J, Thompson ME, Bouthillier M, et al. Improving outcomes in adults with diabetes through an interprofessional collaborative practice program.JInterprofCare2018;32(1):4-13.doi:10.1080/13561820.2017.1372395.

15. Canadian Interprofessional Health Collaborative. National Interprofessional Competency Framework; c2010. Available at: https:// drive.google.com/file/d/1sRKNH81qgHL5-zFPPB8gV4GkRTvCar88/ view (accessed August 21, 2020).

16. Forbes DR, Nolan D. Factors associated with patient-satisfaction in student-led physiotherapy clinics: a qualitative study. Physiother Theor Pract 2018;34(9):705-13. doi: 10.1080/09593985.2018.1423592.

17. Holmqvist M, Courtney C, Meili R, Dick A. Student-run clinics: opportunities for interprofessional education and increasing social accountability. J Res Interprof Pract Educ 2012;2(3):264-277.

18. Simpson SA, Long JA. Medical student-run health clinics: important contributors to patient care and medical education. J Gen Intern Med 2007;22:352-356. doi: 10.1007/s11606-006-0073-4.

19. O'Neill B, Cosgrove D, MacMahon J, Bradley JM. Living well with COPD. Montreal: McGill University Health Centre; 2012. Available at: https:// www.livingwellwithcopd.com/living-well-and-pulmonary-rehabilitation. html ps://www.livingwellwithcopd.com/en/home.html (Accessed December 19, 2020).

20. Jayasheela H, Sivabalan T. Effect of pulmonary rehabilitation on quality of life among the chronic obstructive disease patients admitted at Pravara rural Hospital, Loni (BK). Int J Nurs Educ 2017;9(2):102-7. doi: 10.5958/0974-9357.2017.00045.9.

21. atsjournals.org. New York, NY: American Thoracic Society: Guidelines for the Six-Minute Walk Test; c2002. Available at: https://www.atsjournals. org/doi/pdf/10.1164/ajrccm.166.1.at1102 (Accessed August 21, 2020).

22. Redelmeier DA, Bayoumi AM, Goldstein RS, Guyatt GH. Interpreting small differences in functional status: the Six Minute Walk test in chronic lung disease patients. Am J Respir Crit Care Med 1997;155(4):1278-82. doi: 10.1164/ajrccm.155.4.9105067.

23. Gremeaux V, Troisgros O, Benaïm S, et al. Determining the minimal clinically important difference for the six-minute walk test and the 200meter fast-walk test during cardiac rehabilitation program in coronary artery disease patients after acute coronary syndrome. Arch Phys Med Rehabil 2011;92(4):611-19. doi: 10.1016/j.apmr.2010.11.023.

24. Jones PW, Forde Y. St. George's respiratory questionnaire manual. St. George's University of London; 2009. Available from http://www. healthstatus.sgul.ac.uk/SGRQ_download/SGRQ\%20Manual\%20 June\%202009.pdf (Accessed December 19, 2020).

25. Jones PW, Harding G, Berry P, Wiklund I, Chen WH, Leidy NK. Development and first validation of the COPD Assessment Test. Eur Respir J 2009;34(3):648-54. doi: 10.1183/09031936.00102509.

26. Wilson IB, Cleary PD. Linking clinical variables with health-related quality oflife.JAMA1995;273(1):59-65.doi:10.1001/jama.1995.03520250075037.

27. Anastasaki M, Trigoni M, Pantouvaki A, et al. Establishing a pulmonary rehabilitation programme in primary care in Greece: a FRESH AIR implementation study. Chron Respir Dis 2019;16:1479973119882939. doi: $10.1177 / 1479973119882939$.

28. George L, Bemenderfer S, Cappel M, et al. A model for providing free patient care and integrating learning and professional development in an interprofessional student-led clinic. J Phys Ther Educ 2017;31(2);54-66. doi: 10.1097/00001416-201731020-00007.

29. ccpnr.ca. Charlottetown: Entry-Level Competencies for Licensed Practical Nurses. c2019. Available from http://www.ccpnr.ca/wp-content/ uploads/2019/10/CCPNR-ELCs_2019E.pdf (Accessed August 21, 2020).

30. csrt.com. Ottawa: National Competency Framework for the Profession of Respiratory Therapy. c2016. Available from https://www.csrt.com/ wp-content/uploads/EN_Framework_2016_NARTRB_NCF_Part1.pdf (Accessed August 21, 2020).

31. cna-aiic.ca [Internet]. Ottawa: Framework for the Practice of Registered Nurses in Canada. c2015. Available from https://www.cna-aiic.ca/ / media/cna/page-content/pdf-en/framework-for-the-pracice-of-registerednurses-in-canada.pdf?la=en (Accessed August 21, 2020).

32. Fröberg M, Leanderson C, Fläckman B, et al. Experiences of a student-run clinic in primary care: a mixed-method study with students, patients and supervisors. Scand J Prim Health Care 2017;36(1);36-46. doi: $10.1080 / 02813432.2018 .1426143$. 